ROUNDTABLE

\title{
Open Educational Resources and Open Content for Higher Education
}

\author{
Susan D'Antoni
}

Submission date: November 2006

Published in: April 2007

\begin{abstract}
In this roundtable the author analyzes the specific issues raised in the forum on Open Educational Resources (OER) held in late 2005. The starting point is that UNESCO was created with the mission of fostering a culture of peace, and education is important for UNESCO because well educated citizens will contribute to promoting a culture of peace. In this context it is possible to understand the importance of Open Educational Resources, a term defined by a UNESCO meeting as referring to web-based materials that are offered freely and openly for reuse in teaching, learning, and research. UNESCO's interest in open content began formally with a meeting in 2002 , and the main interest is not necessarily to promote Open Educational Resources, but to provide information about the concept and to develop capacity if individuals or institutions wish to adopt it. The content of Open Educational Resources must be appropriate, and that raises the issues of culture and language if you are considering content from another institution. The learner can access material and contents from the best universities in the world, and the academics will promote internal cooperation in quality control, due to the fact that everyone can see everyone else's materials.
\end{abstract}

\section{Keywords}

open educational resources, cooperation, contents, teaching, learning, research

\section{Recursos educativos abiertos y contenidos para la educación superior abiertos}

\begin{abstract}
Resumen
En esta mesa redonda, la autora analiza los temas especificos que se plantearon en el foro de los Open Educational Resources u OER (Recursos Educativos Abiertos) que tuvo lugar a finales del 2005. El punto de partida radica en que la Unesco se creó para fomentar una cultura de paz, y la educación es importante para la Unesco ya que los ciudadanos que hayan recibido una adecuada educación serán los que contribuyan a promover esta cultura de paz. En este sentido, se puede entender la importancia de los recursos educativos abiertos, un término que la Unesco ba definido como el material basado en red que se ofrece de forma gratuita y abierta para ser reutilizado en la enseñanza, el aprendizaje y la investigación. El interés de la Unesco por los contenidos abiertos comenzó oficialmente tras una reunión que tuvo lugar en el 2002. Su objetivo principal no consiste necesariamente en fomentar los recursos educativos abiertos, sino en ofrecer información sobre este concepto y desarrollar una capacidad en caso de que individuos o instituciones quieran hacer uso de él. El contenido de los recursos educativos abiertos debe ser adecuado, lo que hace surgir cuestiones relacionadas con la cultura y el lenguaje si se considera
\end{abstract}


el contenido de otra institución. El estudiante puede tener acceso a material y contenidos pertenecientes a las universidades más prestigiosas del mundo y los académicos promoverán la colaboración interna en cuanto al control de calidad, debido al hecho de que todos puedan ver el material de los demás.

\section{Palabras clave}

recursos educativos abiertos, colaboración, contenidos, enseñanza, aprendizaje, investigación

\section{Introductory remarks}

First let me say how pleased I am to have been invited to take part in the roundtable discussion on Open Educational Resources. I have known of the Open University of Catalonia since I started my research on the Virtual University and, in fact, Albert Sangrà prepared the case study of your institution. I am also very pleased to have a chance to talk to you about the interesting work that the International Institute for Educational Planning (IIEP) has been doing, which is the formation of a Community of Interest on Open Educational Resources.

I am going to speak about the Internet forum on OER that we held in late 2005 and the specific issues that were raised, and then during our discussion session we can speak more broadly about other issues. But first, I propose to give you a little background information to situate both UNESCO's interest and IIEP's activities related to OER, and then to talk a little bit about what we learned from the discussion forum.

\section{UNESCO ... Its mission}

UNESCO was created with the mission of fostering a culture of peace: this was important in 1945 , and it remains important today. The Education Sector is the largest of the sectors, which is indicative of the importance of education in the work of UNESCO. The philosophy is that well educated citizens will contribute to promoting a culture of peace.

To fulfil its mission, UNESCO act as a laboratory of ideas; a clearing house; a standard-setter; a capacity-builder in Member States - the role of IIEP; and finally, a catalyst for international cooperation - which is why I am very happy to be at UOC today.

\section{IIEP ... Its mission and a study}

IIEP was created in 1967 with the mandate of capacity building in educational planning and management at a time when many countries were assuming the responsibility for their own education systems. The Institute has four main functions: Observation, to look at what is happening in the environment, and what is new in educational planning; Research; Training, which is the principal activity; and Publication. In fact, we have the functions of a university, albeit a tiny one.

In the context of the Observation function, I undertook a study of the virtual university as an example of the growing use of Information Communication Technology (ICT) in higher education. Case studies were commissioned from different regions of the world, with different organisational structures. The cases we received were excellent.

To disseminate the case studies and the number of background chapters we designed a Web publication, the first of IIEP. It was released in 2003, and there has been a great deal of activity on that section of the IIEP site since then, which means that there is considerable interest in the topic.

The web publication and site constituted a resource and a base to support interactivity and stimulate international discussion and debate through a series of Internet forums. The first forum in early 2004 was on Policy issues: What are they? And whose are they? More than 300 people participated. In that discussion it was suggested that Free and Open Source Software should be the next topic of discussion, and a second forum was set up in mid 2004. At the end of that forum, the people involved refused to stop, and the group evolved into an ongoing Community of Interest on FOSS. This community is still alive with 260 people from 60 countries. They are still interacting - not all the time, but when they want- and they are there whenever anyone wants to raise a question or share some information. 
Related to the issue of open-source software is open content, and it was suggested that the third topic of discussion should be Open Educational Resources for higher education. Because of the interest of the Hewlett Foundation in this area, IIEP applied for additional support to undertake a more elaborated activity over a two-year period.

\section{What does Open Educational Resources mean?}

The term was first defined by a UNESCO meeting as referring to web-based materials that are offered freely and openly for reuse in teaching, learning and research. Specifically, it includes content; that is, the materials for learning or reference; tools, the software and delivery mechanisms that support it; and standards, those shared conventions for digital publishing of open resources. The concept of open content has been described as a natural extension of the open-source movement in software and, in fact, higher education shares many of those values of openness and sharing of knowledge.

David Wiley of Utah State University, who has been one of the most active people in this field, says simply, "We should do it because it is the right thing to do. We are here as universities to serve society; we are not here to keep our treasures to ourselves."

\section{Open Educational Resources and the Hewlett Foundation}

The William and Flora Hewlett Foundation has supported a number of the large projects in this area, and they have a vision of the potential of Open Educational Resources. The head of the education programme, Marshall Smith, states that "there is a lot of educational material available on the web but it is rarely organised in a way that can actually help increase the quality of instruction. Open courseware projects allow a professor, anywhere in the world, to see exactly how his or her colleagues present a specific body of knowledge to students. This growing set of resources has the potential to increase the quality of teaching worldwide."

The Foundation describes its program as having the goal "to equalise access to knowledge". That is an important objective and, in addressing it, the work of the Foun- dation aims to remove the barriers to high-quality open content, and to understand and stimulate use. A number of the projects have been described in the report of the IIEP forum. MIT's OpenCourseWare is probably the largest and best-known of all the initiatives. But it is only one model. The Foundation is also starting to support the African Virtual University, which is an initiative started by the World Bank to link African Universities to offer more content through ICT. And, most recently, support has been given to the Open University of the UK in order to put some content on the web in an easily accessible format.

\section{Open Educational Resources and UNESCO/IIEP}

UNESCO's interest in open content began formally with a meeting in 2002 that was convened in Paris to discuss the impact of Open Courseware in developing countries. In the final declaration of the meeting, participants expressed their "wish to develop, together, a universal educational resource, available for the whole of humanity, to be referred to as Open Educational Resources. Following the example of the World Heritage of Humanity, preserved by UNESCO, they hope that this open resource for the future mobilises the whole of the worldwide community of educators."

The interest of UNESCO/IIEP is obviously to help institutions do their job better. It is not necessarily to promote Open Educational Resources, but to provide information about the concept and to develop capacity if individuals or institutions wish to adopt it. It is important to help institutions make informed decisions, and, as a virtual university, you know that the development of online material is exceedingly expensive and making mistakes has costly consequences. IIEP has aimed to support the planning and reflection process on OER in institutions and among individuals.

The primary objective was to increase awareness, because there is no use having openly and freely available material if nobody knows about it. The main goal of the IIEP work is to inform people more broadly. Secondly, we hope to support capacity building and informed decision making.

The project was designed to foster an international dialogue and an exchange of information. And we have done that, or we will do it, in three ways: an initial general forum on OER, a subsequent discussion of key issues, and a second forum on the work done by OECD. 
Regarding the initial forum, if you have looked at the report, then you know how it was organised. It had input from high-level experts because the main objective was to inform people about OER. It was organized as a virtual seminar with input from experts and some time for discussion.

After the forum, a more informal discussion was launched in the Community of Interest that had been formed, and that is the current phase. The first topic discussed was the identification of a research agenda. OER is a new concept, and not much is known about exactly how it can work in an institution. For example, what does it mean for an academic? How can the learner actually use it? There were I Io research questions identified, which were further prioritized in a list of 25 . This work just constitutes a beginning, and needs more work - possibly in a smaller group, and perhaps with a number of individuals and institutions interested in doing research. That was the first activity and it is available on the OER wiki for further work.

The second topic of discussion concerns how to "Do It Yourself" - how to get involved in the OER movement, how to create or reuse materials, how to start, or what to think about. The group is going to look at four questions: Who is it for? What content/resources - what should be in it? How should the content be organized/structured for easy access? How should it be housed/supported - what sort of web site?

The challenge will be to design a feasible resource. The complexity of this current discussion is considerable and it is difficult to synthesise the information; however, an interesting idea has been raised. The building of a "Do It Yourself" resource might be the most important output of this international group.

Next, we are going to ask the FOSS Forum, the Community of Interest on Free and Open Source Software, to reflect on Open Educational Resources and what messages the FOSS movement has for the Open Educational Resources movement. Then both the Communities will be linked to hear what the software people have to say to the content people.

The second organized forum will present the findings of a study undertaken by the Centre for Educational Research and Innovation (CERI) of OECD. CERI has a project to look at the scope of Open Educational Resources, mainly in the OECD countries. A number of research questions will also be addressed: the development of initiatives, sustainable cost-benefit models, intellectual property rights, and improving access and usefulness of OER.

\section{Some initial messages ...}

I would like to present some of the messages from the work of this project so far.

At the conclusion of the forum in 2005 , the group was asked to identify the most important issues to address to advance the OER movement. The developed countries proposed: research, promotion, retrieval tools and sustainability. The developing countries proposed capacity building, promotion, collaborative development, and technical access.

During the discussions, there was a high level of interaction and some very general issues emerged. First, academics must play an important role in this activity, and there must be incentives to promote development of Open Educational Resources. Second, the issue of Intellectual Property Rights was raised as a major concern to academics, who fear that their material will be used without their knowledge and possibly inappropriately.

In academe, the publishing procedure is known and understood, if not always appreciated. But with Open Educational Resources and the publication of material on the web with an open licence, the use is unknown, and there can be a high level of apprehension and resistance.

The costs of developing Open Educational Resources can be high, and in your institution, you know this better than would most traditional institutions. Models for sustainability are needed. For example, MIT is being financed by the Hewlett Foundation for about a million dollars every year. That level of support will not continue forever, so a model has to be found for this type of activity.

From the perspective of UNESCO, the issues of language and culture are very important because currently much of the development is in the North, and much of the use is in the South. This is not a model to perpetuate, and it was very good to hear from participants from developing countries who noted that they would prefer to see collaborative development. Collaborative development of OER could result in material better suited to the needs of all involved. This is an important point and research is needed to illuminate what is happening and how.

Some barriers were identified during the debate. For example, both institutions and academics expressed concern about openness. There is an increasingly commercial and financially competitive environment in higher education. As higher education is rarely adequately funded by the state, institutions have moved to generating revenue themselves, and their intellectual property is seen as an important resource in this context. 
The lack of ICT infrastructure was identified as a particular problem in many developing countries. There is a tension in terms of development between wanting to create very rich digital material and wanting to make it widely available by taking into consideration the constraints related to access in many countries. Nonetheless, there was no dispute among the participants in the forum that Open Educational Resources are very important in global higher education.

In reflecting further on OER, I propose to focus on three of the stakeholders - the learner, the academic, and the institution.

\section{... related to the learner}

From the perspective of the learner, OER has great potential because an independent learner who has an affordable connection to the Internet can access material from some of the best universities in the world, no matter where he or she may be. Under these conditions, access to knowledge is being opened. This is important for lifelong learning; it is important for professional development. And it may be very important in contributing to promoting informal learning, where a credential is not needed. Prospective students may assess institutions by looking at their materials. Students can enhance their learning by exploring the materials made available by other institutions. So, there are clearly benefits for learners. Although they do not receive a formal credential, they can gain access to knowledge, freely and openly.

The discussion was not so clear about the benefits for academics and institutions, and that is an important message from the discussion.

\section{... related to the academic}

Academics play what could be seen as the most important role, because they produce or reuse content. In terms of provision, the forum participants thought it was very important to develop content for the institution and the local context first. Such an approach describes UOC: if I understand the philosophy of the institution, it was created to develop learning opportunities for the local area first, and then to extend its reach to the region and then to the international sphere.

Intellectual property rights constitute another challenge: will academics readily agree to give them away, bearing in mind the concern expressed about how material will actually be used by other people? Within an institution, academics may be reluctant to use materials from someone else. I am going to quote David Wiley again with respect to why academics would want to be involved: "because you can increase your reputation in the field. You are more visible. You can show your excellent work to a wide group of people." He continues: "You can leave an academic legacy to others after your time in academia. You can support the values of innovation, collaboration and openness, which are very good social values. You can help learners without burdening your own schedule. If you create excellent material and you allow people to visit it and use it without contacting you, you are enlarging your impact. And you can make your work a pillar that others can build on."

\section{... related to the institution}

Turning to the institution, one of the potential benefits of OER was seen to be a change in the way in which education is provided. Because everyone can see everyone else's materials, the process can also promote internal cooperation in quality control. If you have a colleague who has excellent course materials put up on the web, and you only have a two page course outline, you may be encouraged to do a little more.

In terms of the provision of OER, the message that came across from the discussion is that the institution must provide leadership and support. This is essential because involvement in OER production or use involves, in most cases, institutional change. Without institutional leadership, there is the risk that there will be a few projects here and there, but primarily, innovation that involves the faculty member as an individual, but not the institution as a whole. Full engagement with OER development and use was seen to require support from the top, and appropriate recognition and reward. The institution has to let academics know about the benefits and the risks, and the institution has to consider whether it can afford to give away its intellectual property, and what that will mean to its economic model.

Quality control is another issue that was raised. When materials are made available on the web, there will be an impact on the reputation of the institution, for better or for worse.

In terms of using OER, the content must be appropriate, and that raises the issues of culture and language if you are considering content from another institution. Concern is expressed by academics about how to adapt content from 
other places in the world. Content needs to be culturally and linguistically translated. And localisation means that it has to be accessible to the learner in his or her own setting. In Europe, this is not an issue, but if you are trying to reach people in a developing country, it is. Collaborative development might well be the solution to those problems.

\section{Closing remarks}

I would like to return to David Wiley's comment on Open Educational Resources: Why should we do it? Because it is the right thing to do.

The interest in Open Educational Resources is relatively high, as could be seen in the discussions in the IIEP forum, and the size of the Community of Interest that has evolved. But there are some concerns, and they are very important ones. They should be considered first. It is a time of important decision-making, and one that will have an important impact on the availability of knowledge in the future.

\section{Debate}

\section{Question}

I would like to know why you decided to break the subject up into four parts: providers, users, intellectual property and the last one, faculty members. Was it the best way to categorise the problems regarding Open Educational Resources? I am asking this because we are working on another project, the OLCOS Project, which has the same focus, but we decided to use completely different approaches. The problem was that if we put the focus on technology we could be missing the development or access aspects of it. It is a big deal because you need to face all possibilities and be sure that you do not miss anything. One of our concerns in this project was how to start and to divide the big problem into little ones, so we could try to solve them. In your case, which are the reasons for this division?

\section{Susan D’Antoni}

My answer has two parts. On one hand, the forum was divided into a reflection on provision and use of OER because it was designed to explain the concept and describe some of the current activity. In fact, many of those parti- cipating indicated that they did not understand the concept of OER. We dealt with "push" first, and then "pull". In addition, I wanted to ensure that we treated some of the many issues that are associated with provision and use. Several were selected just to start the discussion, but they were of such interest that we did not have time to progress beyond them. However, it must be said that the approach used to organize the forum discussion was not intended as a classification of the issues.

On the other hand, the report was written by one person, from his own perspective, with a structure and emphasis that were his own. Discussions are too rich, too time consuming and too complicated to be easily summarized, and reports represent the best efforts of the individual preparing them. But there may be another way to capture forum discussions. A professor from the University of Sao Paolo commented, "I want to tell you what an extremely interesting conversation you are having. It took me three days to read the messages from the beginning, and I took twenty pages of notes." And then he suggested that the threads of the discussion could be captured to create a dialogue. We have tested it, and it will work.

I think that I am answering more than your question, but I want to make the point that it is difficult to organize a discussion so that it is fruitful and informative for all participants, and even more difficult to capture and classify the flow of the discussion in a report.

\section{Question}

You have mentioned the MIT model. Even if it has to be improved, I think that is a push, more than a pull, strategy. So, if in 2006 , we are listening to developed countries, I really can open my work and deal with other people, speak with people in different places all around the world. In this sense, I guess that a pull strategy is a much better way. So, do not you think that maybe this will change the design, the quality of the whole project being pushed or pulled, I mean is it compatible, having the pilot to study these differences?

\section{Susan D’Antoni}

I think as UNESCO, we have to consider both strategies. One of the other problems of the forum is the participants from developing countries not talking, not interacting, even if they are half of the number. But they are not leaving either, so it can be deduced that the interaction is useful to them. 
This is a serious problem and one we also faced when we started the FOSS for e-learning discussion. The discussion started with developed country members doing most of the talking. This is the "push" model, if you will. Maybe collaboration is the secret. It is true that it is not pull, but it is joining all together.

It really is a concern, because if we are talking about open educational resources in the context of increasing access to knowledge worldwide, we have to address the importance of balancing the "push" with a "pull".

\section{Question}

Do you think that a University should go over national or international resources as an institution, or, on the contrary, just leave professors to do it on their own? Should professors, then, wait to be pushed by the organisation, or pull themselves?

\section{Susan D’Antoni}

That is institutional change, and there is more than one way to change. If I underline that it is exceedingly important to have the support of the institution, I am giving you one of the messages that emerged from the IIEP study on the virtual university.

Case studies were commissioned from $\mathrm{I} 2$ institutio$\mathrm{ns}$, and those institutions are still in existence today, even though the study was undertaken at a time when many virtual universities were failing. Leadership from the top becomes even more important if we are talking about traditional institutions with a virtual unit. In this case, the traditional university policies and procedures may not be the most appropriate to support the new initiative - change will be required. Virtual universities such as UOC are different. Many institutions that have developed as open universities are all so different, and may not have the same problem.

Nonetheless, I think that it is good to promote and support individual initiatives, because sometimes the passion of an innovator, when he or she succeeds, will convince everyone else much more easily than saying "you should do that".

\section{Question}

Susan, I just wanted to say that you are kind of worried that not enough pull movement has already been achieved. I don't think you should be worried about the fact that not so many active participants in the virtual discussion have been in this forum as in the previous ones. I would say I am a kind of an example of this. I have been reading and very actively learning from the forum during the few years from 2004. And I always felt that I was kind of not qualified enough to go into the discussions at that very moment. And I always thought that tomorrow will be the day when I will do my posting. But I am absolutely sure that the very idea of such a high-quality conversation on the web, with so many people having access to it, is a very productive thing by itself. I would say this is exactly like this Roundtable, because during these three years, with Josep Maria Duart, we have been commenting, learning, discussing, and that's how we decided to actually bring this conversation to the institutional level. That is also a sign that the institution gives its support by doing this.

And let me just remind everyone that the very idea of this seminar starts, or grows, from our wish to make a Roundtable. It is not exactly, necessarily, a seminar where several prepared talks are delivered, but rather, by definition, a conversation between peers. So I would like to bring a little bit of disorder into this very well-organised structure and invite all of you to be participants of this conversation.

\section{Question}

I think that institutions involved in Open Educational Resources should behave like a little UNESCO. At the beginning of this Roundtable, you, Susan, said that UNESCO behaves as a laboratory of ideas, that innovation, almost in every field, also in education, is about foreseeing individual innovation. In short, that innovation happens on a small scale and, if it works, it will be incorporated by leadership. I think that one of the problems is that we are not used to being open. We know a lot about educational resources, but we do not know much about being open with those resources. So, when you talk about institutional change, I think that that is what we should be promoting at every level.

\section{Susan D'Antoni}

Something I like very much about your institution is the blog of the rector as a means of both internal and external communication. I gave a presentation in London to a Leadership Summit on Higher Education in January, and I spoke about some of the leadership challenges for distance education and e-learning. During the dinner, we 
had a speaker who had been the previous head of a big publishing company. One of the points he made was about internal communication. He said, "We're a publishing company. We're in the business of selling, but I want you to know that we spend more money on internal communication than on marketing." I found this a good lesson for higher education.

\section{Question}

You mentioned that some of the reluctances on the part of the academic community was the fear of losing some kind of control over their scientific output and their publications. However, I would say that scientific authors have never had any full or real control over their ideas, over what other people would do with them. I think this is the whole point of scientific publication. So, in my opinion, there is no need for fear. This is what science is about: other people taking my ideas and doing unexpected things.

\section{Susan D’Antoni}

I think you are right, but I was reporting on the discussion during the forum: academics are worried. While the discussion was about intellectual property rights and copyright, it may really relate to the fact that things are changing and no one is sure what is happening. One of the forum participants said about OER, "It is logical. It is what we do anyway in academe, so what could possibly be the problem?"

\section{Question}

I really think that this dichotomy of ideas between scientific production and other kind of materials is what really complicates the entire subject, and makes the topic so emo- tional. In the academic field we all feel our job is to spread ideas and put them out there for people to use them. But we're not talking about that. We're talking about works, and that is what we all want to have some control over.

I really liked your mentioning of what were the topics that academics were trying or putting up first, and I was quite surprised to see that the first three had to do with ego. I want my name to be up there, and I want people to know what I do. We should put the ego aside although we academics like it very much. And we should not be talking about ideas, either, because we agree that ideas should be there. We should focus on the work, on the sources of the materials.

After all, ideas are free and, depending on the topic, it does not take you much investment to create them. But, for example, when you put something in a digital formal, there is a lot of research, lots of investment going into the creation of these works, these resources.

It has to do not with the natural laws, but with the laws of commerce. If you invest to create something, and the institution puts some work on it, it seems natural to expect that they want to get some income, of return on the investment.

So I think that in the end, this is a story about business, even if there is also a positive side which is about access to knowledge, about cooperation or about development. But the practical issue relates to decreasing institutional costs for developing teaching materials; it is about increasing benefits; it is about how to manage publishing companies. So, in fact, there are strong tensions at this moment, and how to balance them is maybe the key issue about how to manage OER. 


\section{Recommended citation}

D’antoni, susan (2007). "Open Educational Resources and Open Content for Higher Education” [on-line roundtable]. Revista de Universidad y Sociedad del Conocimiento (RUSC). Vol. 4, no. I. UOC. [Date of consultation: $\mathrm{dd} / \mathrm{mm} / \mathrm{yy}]$.

$<$ http://www.uoc.edu/rusc/4/I/dt/eng/dantoni.pdf >

ISSN I698-580X

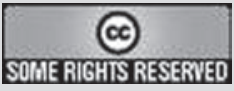

This work is subject to a Creative Commons Attribution-Noncommercial-NoDerivativeWorks 2.5 Spain licence. It may be copied, distributed and broadcasted provided that the author and the source (Revista de Universidady Sociedad del Conocimiento - RUSC) are cited. Commercial use and derivative works are not permitted. The full licence can be consulted on <http://creativecommons.org/licenses/by/2.5/es/deed.en>

\section{About the author}

\section{Susan D'Antoni}

UNESCO International Institute for Educational Planning

s.dantoni@iiep.unesco.org

Susan D'Antoni joined the International Institute for Educational Planning (created by UNESCO in I963) in 1995. Previous to this, her posts included Project Director for a study which sought to identify all sources of correspondence education in Canada. Subsequently, she took up the position of Coordinator of Distance Education Programmes at Ryerson Polytechnical University in Toronto. Moving to the Federal Government, she worked as Chief of Projections and Analysis in the Education, Culture and Tourism Division of Statistics Canada. Then she assumed the position of Director of the newly created Division of Research, Policy and Planning at the Association of Universities and Colleges of Canada. 